\title{
Checking the Performances of Ultrasonic Welding Machines in the Manufacture of Car Wiring
}

\author{
Nicoleta RACHIERU \\ University of Pitesti, Romania, nicoleta.rachieru@upit.ro
}

\begin{abstract}
An important operation of the technological process of manufacturing the car wiring is the ultrasonic welding operation. This is done with the help of a special machine, equipped with a device on which the parts to be welded are placed. By using a sonotrode, that concentrates the waves, the parts are welded together. The machine is checked periodically to determine whether its performance meets the customer's requirements and whether it should be replaced with a newer model. This paper deals with aspects of ultrasonic welding and its application in the manufacture of automotive wiring, the components of ultrasonic welding equipment and welding parameters. In a case study carried out on a wiring that forms part of a car, the performance of the MINIC II ultrasonic welding machine was checked by the two parameters, the degree of compression and the pulling force. After verification it was found that that a new equipment would lead to the reduction of the number of scraps and, implicitly, to a reduction in manufacturing costs.
\end{abstract}

\section{Keywords}

ultrasonic welding, auto wiring, sonotrode, compression degree

\section{Introduction}

The welding process involves a series of physical and chemical phenomena by which a nondemountable assembly is obtained between two elements. In the case of welding of two metal components, an addition material may or may not be used, and a homogeneous bond must be formed between the marginal atoms of the welding parts. The two parts are heated locally to a certain temperature and then, a contact pressure is applied, a condition necessary to perform pressure welding.

There are and have been developed numerous welding processes grouped into two categories: melting welding processes and pressure welding processes. Melting welding consists of heating the contact area between the two parts until melting, without any further pressure on them, while when welding under pressure it is necessary to apply a force to the welding elements, with or without local heating. The ultrasonic welding process belongs to the category of pressure welding methods with mechanical energy.

\section{Principle and Applicability of Ultrasonic Welding}

Ultrasonic welding uses locally applied ultrasonic waves as an energy source on two pieces that are pressed together on their contact surfaces, creating the final joint. The direction of oscillation of highfrequency waves is perpendicular to that of the tightening force of the parts. Ultrasounds are highfrequency vibrations (over 16000 cycles/second) that cannot be perceived by human hearing.

Sound is the process by which pressure waves propagate into elastic materials. The deformation is propagated by the material by coupling the particles in it [1].

By its frequency, the sound is classified into the following categories:

- Infrasound: 0 - $20 \mathrm{~Hz}$;

- Audible sound: $20 \mathrm{~Hz}-20 \mathrm{kHz}$;

- Ultrasound: $16 \mathrm{kHz}-2 \mathrm{MHz}$;

- Hypersound: over $200 \mathrm{MHz}$.

The applicability of ultrasonic welding is very wide and is found in many industrial sectors. The weldability of two materials by this process depends very much on their thickness. If they are too thick, 
they will not be able to be welded together. This type of welding is used in areas such as: electronics and electrical engineering, fine mechanics, reactors, machine-building industry, electrical contacts, electrical terminals, electrical conductor joints that are part of wiring.

The advantages of ultrasonic welding can be treated in technical but also economic terms, and are the following:

- High durability of the weld obtained;

- It is not necessary to prepare the surfaces (grinding, cleaning, degreasing), since the impurities break and are removed during the joint;

- Increase productivity by obtaining considerably lower welding times than by conventional welding processes;

- No additional materials, such as glue, wires or solvents, are required, leading to a reduction in the costs involved in the production process;

- No protection environment (e.g., gas) is required;

- The repeatability of cycles is obtained in exactly the same parameters in which the desired quality of the weld was obtained.

The main disadvantages of this welding process emerge from the fact that the implementation of such equipment requires a considerable initial investment and qualified operators, who can work with the machine.

\section{Components of Ultrasonic Welding Equipment and Welding Parameters}

Ultrasonic welding equipment are generally composed of three indispensable systems:

A) An ultrasonic generator system;

B) A system for pressing parts to be welded;

C) A welding process control and a command system.

A) The system generating ultrasonic waves (figure 1) shall consist of the following elements: Frequency Generator, GU; Bistable circuit, CBB; PA preamplifier; Amplifier A; TN electroacoustic transducer; TP Pressure transducer; BT time-based pulses; Transformers TR1, TR2; CFT frequencyvoltage converter [2].

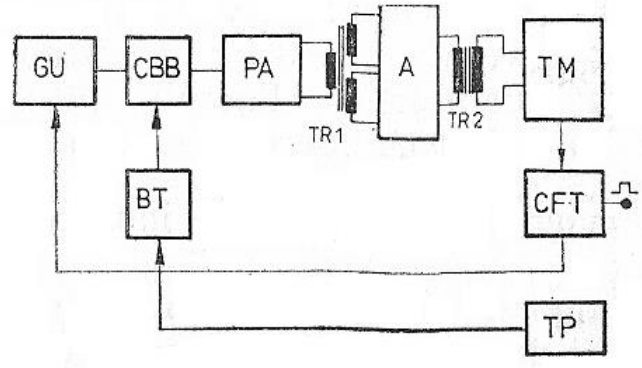

Fig. 1. Diagram of the ultrasound generator system

Such equipment has the following mode of operation. GU generates frequency and voltage signals using the bistable circuit (CBB), the preamplifier (PA) and the amplifier (A). The power is sufficient to excite the electroacoustic transducer (TM). The pressure transducer (TP) measures the contact pressure. TR1 and TR2 (transformers) adapt the impedances of the related circuits. Through the frequency converter (CFT), the negative reaction is carried out in order to determine the frequency of the system [3]. Transductor (TM) is a device that allows the conversion of electrical ultrasonic pulses into mechanical vibrations.

Ultrasonic vibrations are transmitted from the transducer to the support on which the parts to be welded are placed by means of a device that concentrate the received waves. These devices are called sonotrodes and are used to amplify the mechanical oscillations.

B) Pressing together the welding parts for the purpose of ultrasonic welding is done by means of a pressing system, which can operate on mechanical, pneumatic or hydraulic principle, and performs the coupling of the ultrasonic block. 
C) The control system serves to control and ensure the action of the clamping system in a period and the delayed action of the wave generator.

Ultrasonic welding parameters are:

a - The amount of electricity required for the welding process;

$\mathrm{b}$ - Pressing force;

c - Welding time;

$\mathrm{d}$-Amplitude and frequency of ultrasonic vibrations;

e -The resonance phenomenon between the welded parts.

a) The electricity required by the ultrasonic welding process is given by the following relationship:

$$
E=K \times(H \times t)^{\frac{3}{2}}
$$

where

$E$ - amount of electricity [Ws],

$K$ - constant ( $K=150$ for electro-strictive transducers);

$H$ - micro-hardness of materials, in Vickers units;

$t$ - the thickness of the weld piece that comes into direct contact with the sonotrode, in inches [4].

b) The pressing force of the parts to be welded varies according to the characteristics of the materials and their thickness. It increases with the flow limit, and hardness and thickness of materials subjected to ultrasonic welding. The pressing force must not be excessive, so it can cause deformation on the welding components, but not very small, because an insufficient pressure force leads to the slipping of the parts on the sonotrode and generation non-compliant welds.

c) Welding time is the interval during which the ultrasounds are transmitted and varies between 0.05 seconds and 1.0 seconds, depending on the thickness of the welded wires.

d) Amplitude and frequency of ultrasonic vibrations. The required ultrasound frequency is inversely proportional to the thickness of the welded parts. In practice, it has been experimentally found that when welding metals, the frequency should be 18 to $25 \mathrm{kHz}$ and the amplitude should not exceed 20 to $30 \mu \mathrm{m}$. When welding parts not of the same thickness, the welding parameters shall be determined according to the part with the smallest thickness which comes into direct contact with the sonotrode [5].

e) The resonance phenomenon between the parts to be welded. It should be noticed that, in the case of ultrasonic welding, welding parts may resonate. This has consequences such as:

- Non-qualitatively compliant welds;

- The weld could break easily;

- Formation of cracks inside the materials of the welded components.

To avoid this phenomenon, it is possible to change the components placement in the welding machine. Also, it is possible to use supplementary masses to secure the parts in the desired position.

\section{Ultrasonic Welding Operation of Car Wiring}

The welding operation is the stage preceding the sealing operation in the technological process of making car wiring.

No addition material is used for the ultrasonic welding operation (figure 2) and the energy source used is the locally applied ultrasonic waves on two or more non-insulated ends of the electrical conductors, which are pressed together on their contact surfaces, creating the final joint.

The operation is performed on the ultrasonic welding machine type Minic II (figure 3). The Minic II ultrasonic welding machine is manufactured in 2012, designed by Schok Sonosystems to weld conductors made of non-ferrous materials [6]. To operate this machine, the stages are:

I) Machine set-up. The values for cable sections parameters are entered manually in machine software. For example, $S=2 \times 2.035 \mathrm{~mm}^{2}=0.7 \mathrm{~mm}^{2}, S$ being the cumulative section for the two wires. This means that two cables with $0.35 \mathrm{~mm}^{2}$ section are welded. The machine automatically sets the welding parameters such as amplitude, energy, and the width of the welding node.

II) Welding phase (figure 4). The end strip of electrical conductors are placed on top of each other on the sonotrode (the one with the largest section is placed first, directly on the sonotrode, and the others 
sit on top of the first, in descending order of section size), then the foot pedal is pressed. Welding takes place in less than a second. The weld can be at the end (figure 5) or in extension (figure 6).

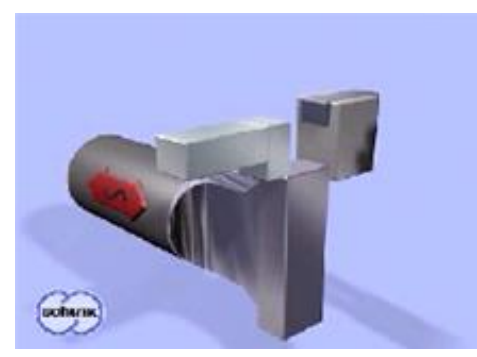

a) Welding device, in open position

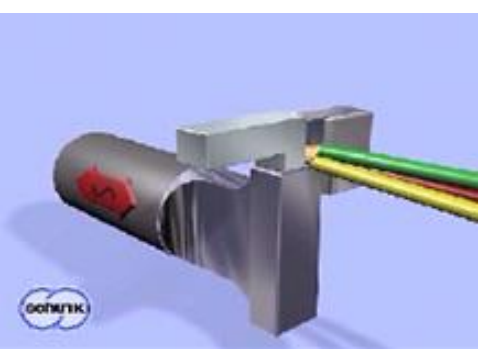

b) Measuring of the cross-section cable

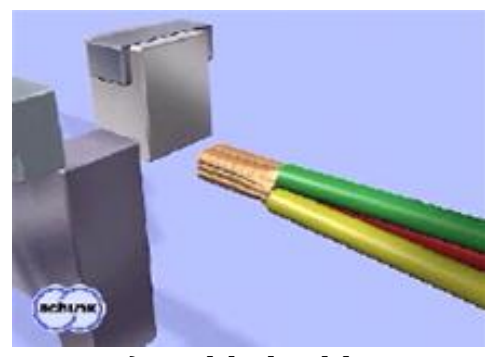

c) Welded cables

Fig. 2. Stages in ultrasonic welding [7]

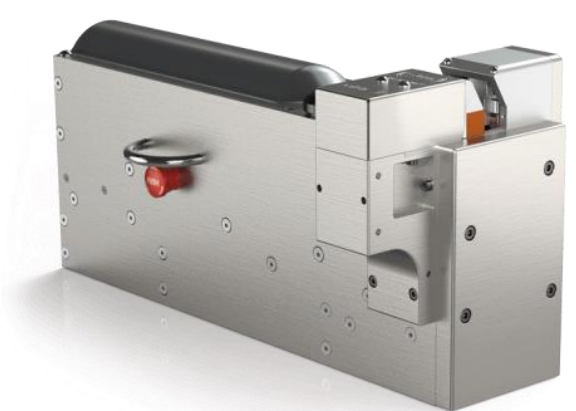

Fig. 3. Ultrasonic welding machine Minic II

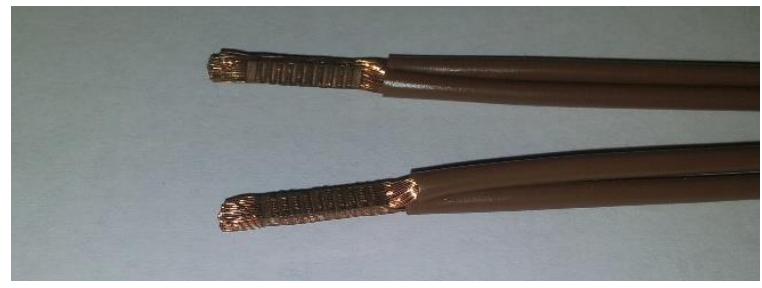

Welding area

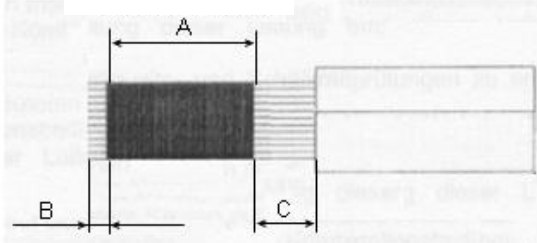

Fig. 5. End welding

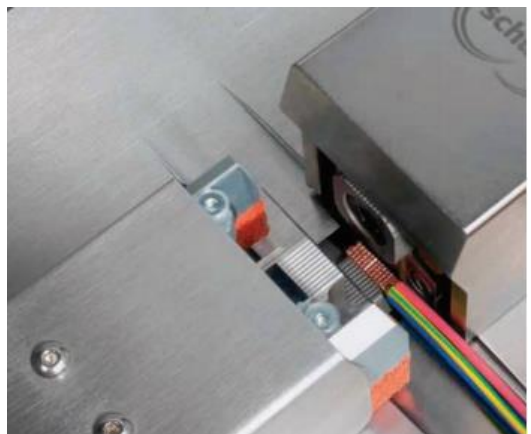

Fig. 4. View of wires placed in the welding machine

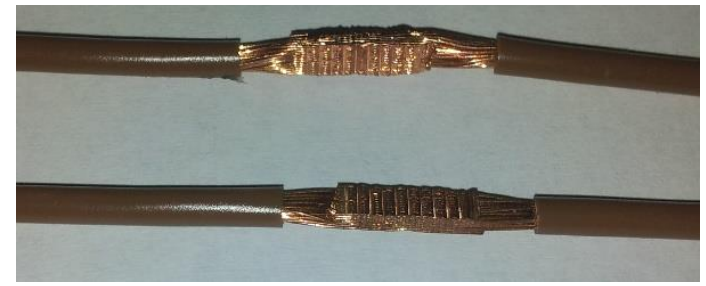

Welding area

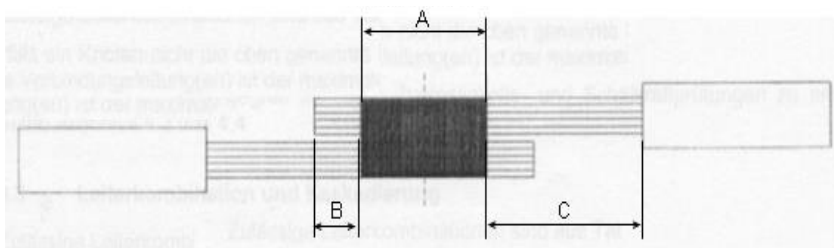

Fig. 6. Extension welding

III) Welding verification. In this stage, under microscope, the welding is checked for defects. After that, the tensile resistance test is carried out, and the degree of compression of the conductive cores, both with a frequency of $1 / 10$.

\section{Checking the Performance of the Minic II Machine. Case Study 5.1. Choosing samples for welding and testing}

To check the performance of welding machines, a series of welded samples are chosen for testing. The combination of two section cables $0.35 \mathrm{~mm}^{2}$ are selected for the purpose of tensile verification and compression determination. This combination will be analysed in both end welding and extension welding. 
A set of 50 samples is selected for each type of welding with following dimensions (in accordance with figures 5 and 6) $\mathrm{A}=11 \mathrm{~mm}, \mathrm{~B}=1 \ldots .4 \mathrm{~mm}, \mathrm{C}=2 \ldots 5 \mathrm{~mm}$, which will be ultrasonic welded under the following conditions:

- all cables used will come from the same manufacturer;

- cables must not be more than eight months old after manufacture or more than eight weeks old from the date of their cutting;

- smoothing with fingers the striped disinsulated lengths to be welded must be avoided;

- the cables must be straight;

- not a single conductor shall emerge from the welding node.

For experimental testing are used cables with a length of $300 \mathrm{~mm}$, striped at one end over a length of $16 \pm 1 \mathrm{~mm}$, but keeping the cap until the actual welding in order to protect the conductive core against external factors (moisture, dust, oil, etc.).

\subsection{Degree of compression determination}

The pressure required for ultrasonic welding of the electrical conductors will influence the degree of compression of the welding node. If the degree of compression is too small, the node will have a diameter greater than the cumulative diameter of the welded conductors, which will lead to poor tensile strength and, by implication, generation of non-compliant welds. If this degree is too high, deformations occur in the welding node, and the resistance, diameter and electrical conductivity of each individual wire could be compromised.

The degree of compression must be adapted in such a way as to obtain certain mechanical and electrical properties required by the customer's standards. From this point of view, for optimal results, the compression degree must be $86 \ldots 96 \%$ of the cumulative diameter of the welded conductors.

The compression degree calculation is determined using the following relationship:

$$
Q=100 \times \frac{A_{0}}{A_{1}} \%
$$

where:

$Q$ - compression grade;

$A_{0}$ - total section (cumulated), sum of individual cross-sections:

$$
A_{0}=\sum_{j=1}^{m} A_{j}
$$

$A_{j}$ - single conductors section, $\mathrm{j}=1,2, \ldots, \mathrm{m}$ :

$$
A_{j}=\left(\pi \times d_{j}^{2}\right) / 4
$$

$d_{j}$ - diameter of the single conductor (wire) - determined by measurement;

$m$ - number of wires in the cable (figure 8);

$b$ - height of the welding node;

$h$ - width of the welding node;

$A_{s}$ - section of the welding node (figure 7 ), resulting from calculations:

$$
A_{s}=b \times(h-0.2) \text {. }
$$

In the previous relation, $0.2 \mathrm{~mm}$ are subtracted from width $b$ and from height $h$ of welding node to take out the influence of the surface structure.

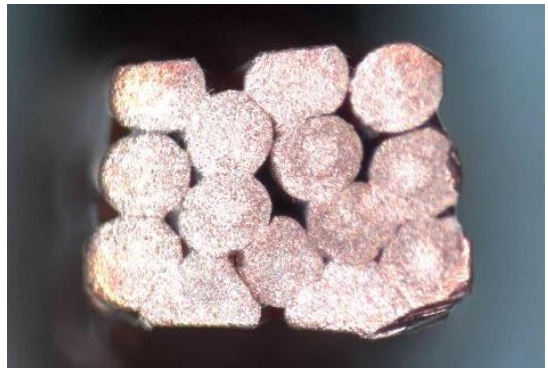

Fig. 7. Section of welding node

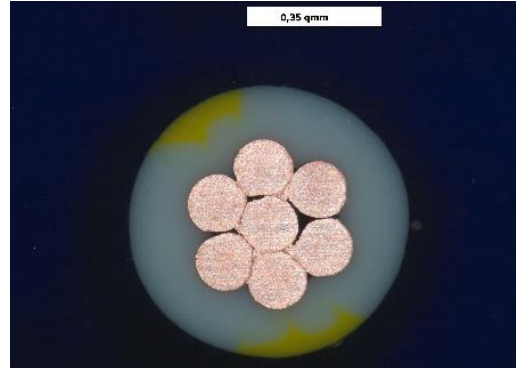

Fig. 8. Seven wires core 
RECENT, Vol. 22, no. 1(63), 2021

The data obtained from the measurement of the diameter and calculation of the cross-section $A_{m}$ of the singular conductors that make up the conductive core of the first and last sample studied are presented in Table 1 and Table 2 respectively.

Table 1. Diameter and individual section for the first sample

\begin{tabular}{|c|c|c|}
\hline $\begin{array}{c}\text { Wire } \\
\text { number }\end{array}$ & $\begin{array}{c}\text { Measured } \\
\text { diameter }[\mathrm{mm}]\end{array}$ & $\begin{array}{c}\text { Cross-section } \\
\left(\mathrm{A}_{\mathrm{m}}\right)\end{array}$ \\
\hline $\mathrm{d}_{1}$ & 0.248 & 0.048 \\
\hline $\mathrm{d}_{2}$ & 0.248 & 0.048 \\
\hline $\mathrm{d}_{3}$ & 0.250 & 0.049 \\
\hline $\mathrm{d}_{4}$ & 0.251 & 0.049 \\
\hline $\mathrm{d}_{5}$ & 0.249 & 0.049 \\
\hline $\mathrm{d}_{6}$ & 0.250 & 0.049 \\
\hline $\mathrm{d}_{7}$ & 0.248 & 0.048 \\
\hline $\mathrm{d}_{8}$ & 0.249 & 0.049 \\
\hline $\mathrm{d}_{9}$ & 0.249 & 0.049 \\
\hline $\mathrm{d}_{10}$ & 0.251 & 0.049 \\
\hline $\mathrm{d}_{11}$ & 0.250 & 0.049 \\
\hline $\mathrm{d}_{12}$ & 0.248 & 0.048 \\
\hline $\mathrm{d}_{13}$ & 0.249 & 0.049 \\
\hline $\mathrm{d}_{14}$ & 0.252 & 0.048 \\
\hline \multicolumn{2}{|c}{} & $\mathbf{A}_{\mathbf{0}}=\mathbf{0 . 6 8 2}$ \\
\cline { 2 - 3 } & &
\end{tabular}

Table 2. Diameter and individual section for the last sample

\begin{tabular}{|c|c|c|}
\hline $\begin{array}{c}\text { Wire } \\
\text { number }\end{array}$ & $\begin{array}{c}\text { Measured } \\
\text { diameter }[\mathrm{mm}]\end{array}$ & $\begin{array}{c}\text { Cross-section } \\
\left(\mathrm{A}_{\mathrm{m}}\right)\end{array}$ \\
\hline $\mathrm{d}_{1}$ & 0.249 & 0.049 \\
\hline $\mathrm{d}_{2}$ & 0.248 & 0.048 \\
\hline $\mathrm{d}_{3}$ & 0.248 & 0.048 \\
\hline $\mathrm{d}_{4}$ & 0.251 & 0.049 \\
\hline $\mathrm{d}_{5}$ & 0.250 & 0.049 \\
\hline $\mathrm{d}_{6}$ & 0.250 & 0.049 \\
\hline $\mathrm{d}_{7}$ & 0.245 & 0.048 \\
\hline $\mathrm{d}_{8}$ & 0.251 & 0.049 \\
\hline $\mathrm{d}_{9}$ & 0.249 & 0.049 \\
\hline $\mathrm{d}_{10}$ & 0.251 & 0.049 \\
\hline $\mathrm{d}_{11}$ & 0.246 & 0.048 \\
\hline $\mathrm{d}_{12}$ & 0.248 & 0.048 \\
\hline $\mathrm{d}_{13}$ & 0.249 & 0.049 \\
\hline $\mathrm{d}_{14}$ & 0.247 & 0.048 \\
\hline & & $\mathbf{A}_{\mathbf{0}}=\mathbf{0 . 6 8 1}$ \\
\hline
\end{tabular}

Measurements were made using the Mitutoyo micrometre, with the value of the division $v_{d}=0.01$. Following the measurement of the size of the weld node obtained, the results presented in Tables 3 and 4 were obtained.

Table 3. Results for the first sample

\begin{tabular}{|l|l|}
\hline End welding & Extension welding \\
\hline$b_{1}=0.881 \mathrm{~mm} ; h_{1}=1.028 \mathrm{~mm} ;$ & $b_{2}=0.900 \mathrm{~mm} ; h_{2}=1.015 \mathrm{~mm}$ \\
\hline$A_{s}=0.881 \times(1.028-0.2)=0.7294 \mathrm{~mm}^{2}$ & $A_{s}=0.900 \times(1.015-0.2)=0.7335 \mathrm{~mm}^{2}$ \\
\hline$Q_{1}=100 \times(0.682 / 0.7294)=93.5 \%$ & $Q_{2}=100 \times(0.682 / 0.7335)=92.97 \%$ \\
\hline
\end{tabular}

Table 4. Results for the last sample

\begin{tabular}{|l|l|}
\hline End welding & Extension welding \\
\hline$b_{1}=0.887 \mathrm{~mm} ; h_{1}=1.021 \mathrm{~mm} ;$ & $b_{2}=0.889 \mathrm{~mm} ; h_{2}=1.019 \mathrm{~mm}$ \\
\hline$A_{s}=0.887 \times(1.021-0.2)=0.7282 \mathrm{~mm}^{2}$ & $A_{s}=0.889 \times(1.019-0.2)=0.728 \mathrm{~mm}^{2}$ \\
\hline$Q_{1}=100 \times(0.681 / 0.7282)=93.52 \%$ & $Q_{2}=100 \times(0.681 / 0.728)=93.5 \%$ \\
\hline
\end{tabular}

By using the Minic II welding machine, for the combination $2 \times 0.35 \mathrm{~mm}^{2}$ the following average compression degrees were obtained:

$>$ At end welding: $Q_{\text {med }}=93.51 \%$

$>$ At extension welding: $Q_{\text {med }}=93.235 \%$

\subsection{Tensile welding test}

The tensile testing of the weld obtained is carried out in order to determine at what maximum force the welding node resists by using of a special MAV device. The test is destructive in nature. Therefore, wires can no longer be used. 
The two cables are each be attached to a vise of the appliance, then set, according to internal standards, the speed of the force to $50 \mathrm{~mm} / \mathrm{min}$. The maximum force at which the weld node resists is called tensile force.

Table 5 shows the tensile forces obtained for the samples welded using the Minic II machine.

Table 5. Tensile forces for the samples welded with Minic II machine

\begin{tabular}{|c|c|}
\hline $2 \times 0.35 \mathrm{~mm}$ - end welding & $2 \times 0.35 \mathrm{~mm}$ - extension welding \\
\hline Tensile force [N] & Tensile force [N] \\
\hline 21.6 & 82.6 \\
\hline 20.8 & 81.4 \\
\hline 26.8 & 70.8 \\
\hline 25.5 & 86.8 \\
\hline$\ldots \ldots$ & $\ldots \ldots$. \\
\hline 21.4 & 83.8 \\
\hline 22.6 & 86.2 \\
\hline 26.4 & 77.5 \\
\hline 24.6 & 78.0 \\
\hline
\end{tabular}

For end welding, an average tensile force value of $22.756 \mathrm{~N}$ was obtained. For extension welding, an average tensile force value of $82.786 \mathrm{~N}$ was obtained. The minimum pull force at the end weld must be $21 \mathrm{~N}$, and in extension welding $75 \mathrm{~N}$, for the chosen combination [8].

In the case of end welding, the tensile force obtained was less than $21 \mathrm{~N}$ for seven of the samples tested, which means that $14 \%$ of samples are non-compliant.

In the case of extension welding, the tensile force obtained was less than $77 \mathrm{~N}$ for seven of the samples tested, which means that $14 \%$ of samples are non-compliant.

\section{Conclusion}

Any production process must have, as outputs, products of a quality that meet the requirements of customers, at a competitive price and be carried out as quickly as possible. Companies are interested in being profitable, to obtain the highest profits, so the number of scrap parts must be as small as possible. Most are oriented, depending on profit, towards retrofitting, towards equipping with high-performance equipment and, in this direction, the market comes with a rich offer. For the verified Minic II welding machine there is the possibility of replacing with a newer variant Minic III leading to zero scrap.

\section{References}

1. https://stabbing.ru/ro/instructions/what-is-ultrasonic-welding

2. Sahoo S.K., Satpathy M.P. (2020): Ultrasonic Welding of Metal Sheets. CRC Press, ISBN 978-036-726-577-9, https://doi.org/10.1201/9780429294051

3. Lefter E. (2006): Alimentarea cu energie electrică a autovehiculelor (Power supply to motor vehicles). Editura Mediamira, ISBN 973-713-1495, Cluj-Napoca (in Romanian)

4. Banu I. (2012): Tehnologia materialelor (Materials technology). Editura Universitătii din Piteşti, ISBN 978-606560-290-5 (in Romanian)

5. Bodea M. (2016): Sudura și procedee conexe (Welding and related processes). Editura UT Press, ISBN 978-606737-143-7, Cluj-Napoca (in Romanian)

6. https://www.schunk-sonosystems.com/en/products/product-detail/cc portofolioselektorsono/show/ Product/minic-ii/

7. Schunk Sonosystems (2012): Minic II - Operating manual

8. Standard BMW Group (2009): Ultrasonically welded joint, Ultrasonic welding, Wiring harness 